\section{Brain power for astronomy}

\section{W. H. McCrea}

The Place of Astronomy in the Ancient World. (A Joint Symposium of the Royal Society and the British Academy.) Edited by F. R. Hodson. Pp. 276+25 Plates. (Oxford University: London, 1975) (Published for the British Academy.) £13.

'Astronomy in ancient literate societies' (Part I) starts with a useful introduction to needed astronomical concepts and closes with an account of two uses of ancient astronomy, both contributions by $R$. R. Newton. These ensure maximum comprehensibility of the work and appreciation of some of its objects, the two chosen by Newton being the study of the non-gravitational acceleration of the Earth and Moon, and the study of chronology, particularly from ancient eclipse records. The intervening contributions are on Babylonian mathematical astronomy, Babylonian observational astronomy, ancient Egyptian astronomy, astronomy in ancient and medieval China, and Mayan astronomy in central America. For most readers the striking general features must surely be the widespread character of astronomy in the ancient world and the inference that scientific astronomy in Greece, India, Islam and western countries was so much derived from Assyrian and Babylonian astronomy. Indeed, there is no chapter on Greek astronomy as such; presumably the characteristic Greek contribution is to be regarded as one of interpretation rather than discovery.

Part II is on 'Ancient astronomy: unwritten evidence' with contributions on 'Neolithic science and technology', 'Polynesian and Micronesian astronomy', 'Prehistoric monuments in western Europe'. 'Astronomical alinements in Britain, Egypt and Peru', 'Archeological tests on supposed prehistoric astronomical sites in Scotland'. These deal with the most recent sort of studv of ancient astronomy and that which has attracted most popular attention. There follows a chapter by H. H. Lamb on 'Climate, vegetation and forest limits in early civilised times' and one by D. G. Kendall on 'Hunting quanta'. These two are highly relevant in topic and they show the extraordinary range of science that has to be brought to bear on the problems concerned. The investigation as to whether the dimensions of megalithic sites reveal the use of a quantum
(5.44 feet, $1.66 \mathrm{~m})$ demands novel mathematical statistics of subtle ingenuity (but it seems not to have been tested by re-discovering the foot or the metre!). The book includes brief reports of some informed discussion at the meeting.

Within the allotted space, the book provides surely the best possible accounts of its topics. It is a feast of learning and scholarship, strongly spiced with wit and wisdom. It is thought-provoking in innumerable ways; some of these are noted in the concluding remarks by D. G. King-Hele and by $\mathrm{S}$. Piggott from the sides of the physical scientists and the archaeologists. Naturally one of the most obvious features of some of the unwritten evidence is its uncertainty. On the whole, readers may be inclined to agree with King-Hele that some features of prehistoric sites did indeed mark extreme rising and setting points of the Sun and Moon, and the like, whereas a connection with eclipse prediction seems less likely. As regards the alinements, E. W. MacKie in his contribution remarks explicitly on the difficulties of the subject, but he then asserts: "The plausibility or otherwise of these alinements is something all can assess by visiting the sites". Actually a party of Cambridge undergraduates did subsequently visit some of the sites and came away rather dubious about the alinements (M. E. Bailey et al., Nature, 253, 431, 1975). But MacKie's assertion is surprising because the problem tackled by Kendall is the most straightforward in the subject and yet all his powerful statistical apparatus is unable to produce a definite conclusion from the available evidence. All the other inferences about the sites seem to be $a$ fortiori quite indefinite-but fascinating and deserving of the most thoroughgoing investigation.

The brain power of even the most ancient of the peoples concerned-as King-Hele says-cannot have been appreciably different from that of our contemporaries. This raises all manner of questions about the progress of knowledge and understanding of the astronomical world. Our knowledge is more than that of the ancients, but is our ignorance as great as theirs? Does almost constant brain power produce accelerated growth of technique and accompanying increase in knowledge? Or do developments occur in fits and starts with peaks of knowledge and understanding and great gaps between the peaks? Is our knowledge placed on record in such a way that people 3,000 years hence will be aware of what we know much better than we are of what people knew 3,000 years ago? This book will provide material for endless debates.
Scientific Research in British Universities and Colleges I974-75

At a time when utilization of expertise is greater than ever before, these volumes form a guide to the location of experts, and help to avoid duplication of effort. They cover an enormous sector of the research field with economic as well as scientific/engineering aspects listed, so they have wide application in industry, commerce and public service as well as in the academic world.

Volume I, (Physical Sciences) Covers pure and applied sciences from Aeronautics and Astronomy to textile Technology.

$£ 14.80(£ 15.55)$

Volume II (Biological Sciences) Includes a wide range of agricultural and medical subjects among its 46 groupings

$£ 11.25(£ 11.87)$

Volume III (Social Sciences) Includes research from government departments and many non academic institutions as well as work from Ph.D. students: subjects listed include Business; Industrial and Management Studies, Economics, Education, Law and Social Medicine.

$£ 10.65(£ 11.27)$

\section{Peaceful Nuclear Explosions IV}

Proceedings of a Technical Committee. Vienna 20-24 January 1975 IAEA Publication $£ 13.50$ (£13.98)

\section{Promoting Health in the Human Environment}

A review based on the Technical Discussions held during the Twenty-Seventh World Health Assembly 1974.

WHO Publication

$£ 1.80(£ 1.91)$

\section{Natural Environment Research Council \\ Institute of Terrestrial Ecology}

\section{Annual Report 1974}

Reviews the first year of the ITE, covering areas such as vertebrate and invertebrate ecology, plant biology, soil science, analytical services and research and development.

$£ 2.75\left(£ 3.03 \frac{1}{2}\right)$

\section{Prices in brackets include postage}

Post your orders to HMSO, PO Box 569, London SE1 9NH. Government publications and those of certain International organisations can be obtained from HMSO Bookshops/Agents or booksellers.

See the Bookseller section of Yellow Pages for your nearest stockist. 